\title{
THYROID FUNCTION ASSAY WITH RADIOIODINE. I. PHYSICAL BASIS OF STUDY OF EARLY PHASE OF IODINE METABOLISM AND IODINE UPTAKE ${ }^{1}$
}

\author{
BY T. H. ODDIE, 2 I. MESCHAN, AND J. WORTHAM \\ (From the Department of Radiology and Department of Medicine, \\ University of Arkansas, Little Rock, Ark.)
}

(Submitted for publication May 7, 1954 ; accepted August 30, 1954)

The factors which limit the diagnostic accuracy of radioactive iodine tracer studies may be summarized as follows:

1. There is probably a continuous gradation between the normal and the abnormal with no sharp borderlines between, so that it may not always be possible to establish abnormality.

2. The tests usually attempt to quantitate uptake of ${ }^{121}$ I by the gland, or percentage conversion of inorganic ${ }^{181}$ I to protein bound iodine, but do not actually assay whether or not the thyroid is secreting the hormone in required amounts.

3. There may be present quite large experimental errors.

4. Unknown dietary or other factors may cause confusion.

The first two factors will not be rectified by good experimental accuracy, but some enhance.nent of diagnostic accuracy in available tests will assist materially in the overall evaluation of the problem.

Although many different types of radioiodine tests have been described (1), the scope of this paper is restricted to the early period up to 24 hours after injection of the tracer dose. Technical improvements would be of particular benefit if applied to observations made in this early period, because such tests give an earlier decision. An early thyroid uptake test of this type has been described by Haigh and his coworkers (2-4), and much improved versions more recently by Berson, Yalow, Sorrentino, and Roswit (5), and Clarke and Aujard (6). Loverdo (7) also uses a similar technique, but gives no diagnostic results.

Berson, Yalow, Sorrentino, and Roswit's (5)

1 University of Arkansas Research Series No. 1006. Assisted by Grant C-1866 from the National Health Institute, Division of Research Grants.

2 Fulbright Fellow. excellent method covers the period up to 30 minutes from the time of injection, and it has seemed well worthwhile to extend this method to cover a variable period up to 24 hours after administration. These longer times allow a more accurately measurable amount of radioactivity to accumulate in the thyroid gland when the rate of uptake is small. Small uptake rates occur in hypothyroid cases and also in some patients with cardiac disease.

A major difficulty in the early thyroid uptake test arises from the need for a close estimate of the effect of radioiodine in the neck tissues other than the thyroid gland. These tissues may contribute over half the total in vivo counts over the neck in the early stages of uptake measurements, not only on cardiac or hypothyroid patients, but also on many normal subjects. It is quite common practice to measure the counting rate over the thigh and to assume that this is equal to the rate over the neck tissues, but we have been unable to correlate these two counts closely enough. Accordingly, our approach has been first to study the variation of counts over the neck in a number of test cases and then to try to reduce these counts by careful collimation to a level low enough to enable average values to be applied for all patients.

The matters requiring preliminary study, then, are the uncertainty persisting in the early metabolism of iodine, and the manner of its movement in the neck tissues; the first part of this paper describes the mathematical and experimental basis for the investigation of these particular problems; and the second part includes a description of the routine simplified test methods finally developed.

\section{METABOLIC RELATIONS}

\section{Choice of metabolic schemes}

The metabolic course followed by a tracer dose of iodide placed initially in the human blood stream has been dis- 


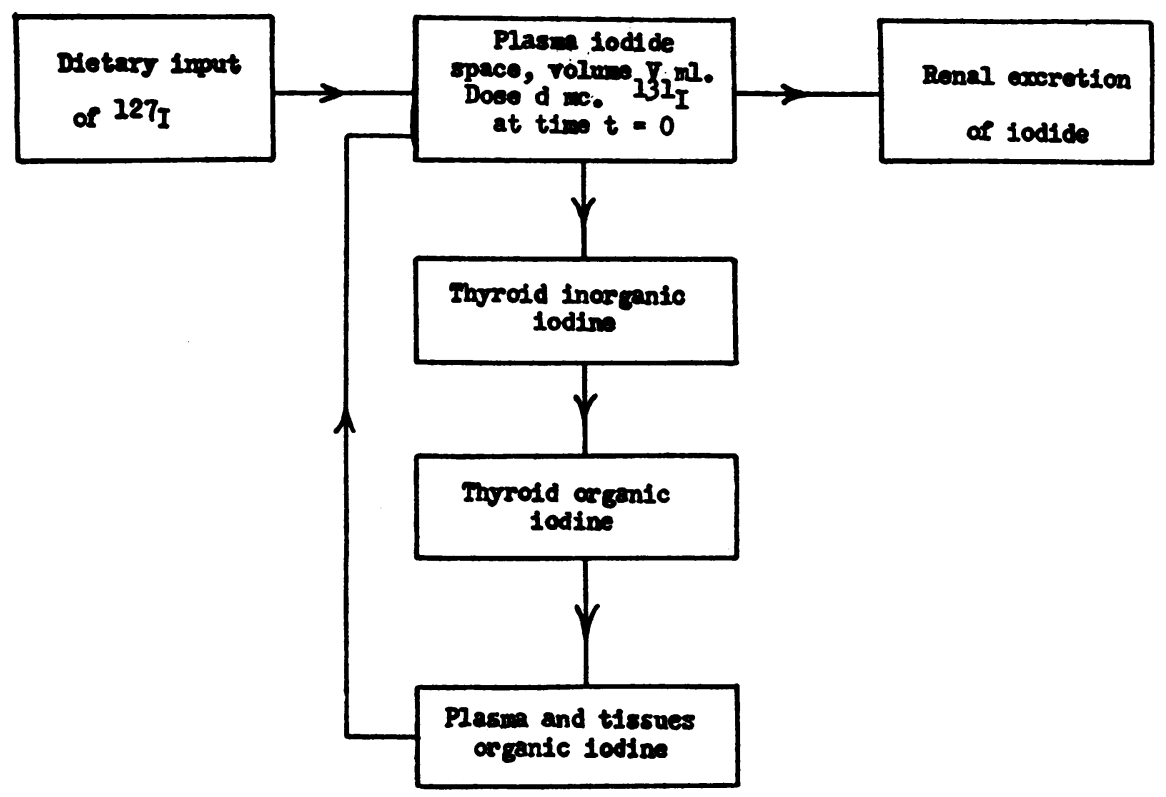

Fig. 1. Complete Approximate Scheme of Iodine Metabolisk

cussed previously on a mathematical basis by several writers $(1,8-12)$; the reader is referred to a recent review by Riggs (1) for a full discussion of this subject. The overall metabolic scheme is generally agreed to be as shown in Figure 1, provided some minor simplifying assumptions are made, chiefly as follows:

1. The initial tracer dose ( $\mathrm{d} \mathrm{mc}$.) mixes with negligible delay at zero time $(t=0)$ with the initial volume of blood plasma $\left(V_{0} \mathrm{ml}\right.$.) throughout the circulatory system.

2. Losses of radioiodine through respiration, or via saliva, sweat or feces are neglected.

3. Iodine may be assumed not to be reabsorbed from urine in the bladder.

The equivalent volume of the "iodide space" ( $\mathrm{V} \mathrm{ml}$.) through which the circulating radioiodide is distributed, varies with time, increasing from $V_{0}$ at time $t=0$. Thus the complete metabolic equations, to account for all the variables over a large range of time, involve too many exponential terms to be evaluated with any degree of accuracy in practice. The problem can, however, be studied in sections by making further more critical assumptions; in several earlier analyses $(1,9,10,12) \mathrm{V}$ was assumed constant, so that the equations developed account approximately for the behaviour of the test dose in the later metabolic stages, but they are not sufficiently accurate for the early phase. On the other hand, Brownell's analysis $(8,11)$ deals with the early phase, prior to the slow output of appreciable amounts of organically bound iodine from the thyroid gland, by breaking up V into a two-compartment system as shown in Figure 2,

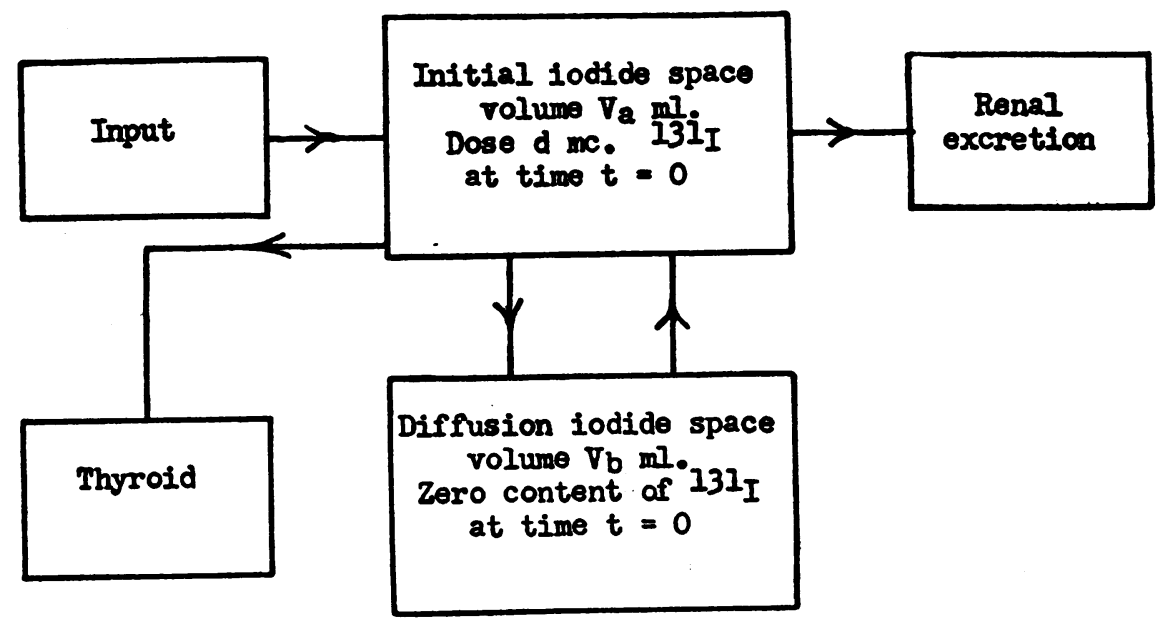

Fig. 2. Brownell's Scheme for Eardy Phase of Iodine Metabolisy 


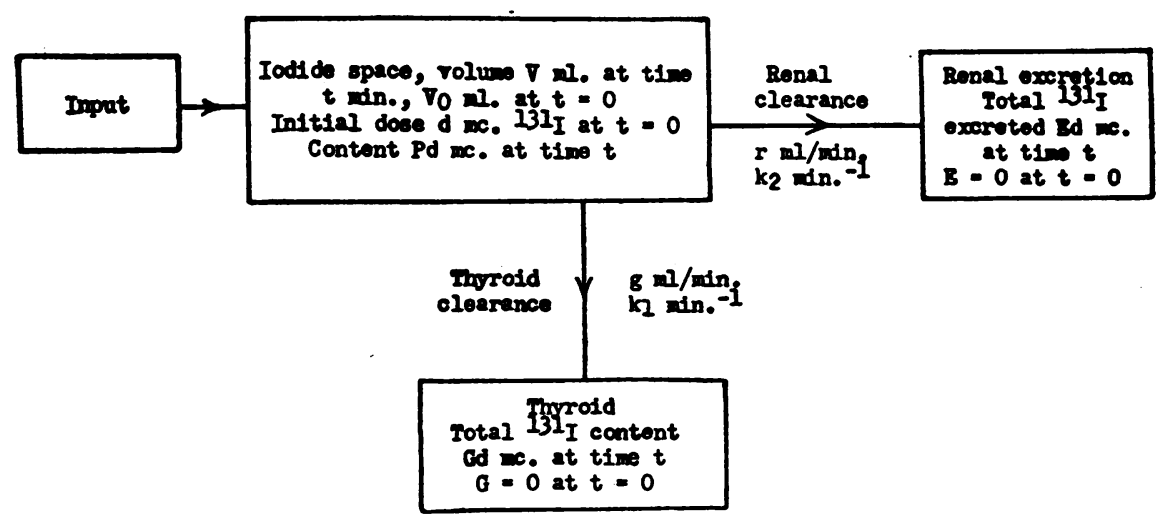

Fig. 3. Scheme Discussed in this Paper for Early Phase of Iodine Metabolisy

where diffusion takes place back and forwards between $V_{c}$ and $V_{b}$. The resulting equations are undoubtedly closer to the truth than those with constant $V$, but unfortunately we have been able to make them fit neither our own experimental measurements nor the data on $\mathrm{V}$ published by Berson, Yalow, Sorrentino, and Roswit (5). It seems that a multi-compartment diffusion system is really required for the iodide space, and it is, therefore, preferable, in our opinion, to deal with the problem experimentally, making no assumptions about the analytical form for the variation of $\mathrm{V}$ with time. In other words, we begin with the scheme of Figure 3 for the early phase of iodide metabolism, before any appreciable tracer has left the thyroid in organic form.

\section{Symbols used}

For convenience, the symbols used in the discussions to follow are listed alphabetically below:

a $\mathrm{ml} . / \mathrm{min} .=\mathrm{g}+\mathrm{r}=$ Combined clearance rate, that is the volume of plasma cleared of iodide per minute by the thyroid and kidneys together.

$\mathrm{d}$ mc. = Net amount of 1 In injected.

$\mathrm{E}=$ Fraction of the dose $\mathrm{d}$ excreted by the kidneys up to time $t$.

$\mathbf{G}=$ Fraction of the dose $\mathrm{d}$ taken up by the thyroid up to time $t$.

g ml./min. = Thyroid rate of clearance of iodide from plasma.

$k \min ^{-1}=k_{1}+k_{2}=$ Average combined (thyroid plus kidneys) fractional rate of removal of radio-iodide from the iodide space during the time interval $t=0$ to 30 minutes; that is, an average fraction $k$ of the circulating iodide pool is removed each minute.

$k_{1} \min ^{-1}=$ Average fractional rate of uptake by the thyroid from $t=0$ to 30 minutes.

$k_{2} \min .^{-1}=$ Average fractional rate of renal excretion from $t=0$ to 30 minutes.

$\mathrm{N}=$ Fraction of the dose $\mathrm{d}$ observed in the neck by external counting at time $t$, including both thyroid and extra-thyroid tissues.

$\mathrm{N}_{0}=$ Initial value of $\mathrm{N}$ at time $\mathrm{t}=\mathbf{0}$ assuming instantaneous mixing of the dose with the circulating plasma.

$\mathrm{N}_{2}=$ Value of $\mathrm{N}$ at $\mathrm{t}=2$ minutes.
$\mathrm{N}_{2,10}=$ Average value of $\mathrm{N}$ between 2 and 10 minutes.

$P=$ Fraction of the dose $d$ remaining in the iodide space at time $t$.

p ml. $.^{-1}=$ Fraction of the dose $\mathrm{d}$ remaining in the plasma iodide space at time $t$, per unit volume of plasma.

$\mathbf{R} \mathbf{m c}$. = Content of the $1 \mathrm{II}$ source prepared for purposes of calibration.

$\mathrm{r} \mathrm{ml} . / \mathrm{min} .=$ Renal rate of clearance of iodide from the plasma.

$t$ min. $=$ Time from injection of the test dose.

$\mathrm{V} \mathrm{ml}$. = Volume of the total apparent iodide space at time $t$.

$\mathrm{V}_{0} \mathrm{ml} .=$ Initial value at $\mathrm{V}$ at $\mathrm{t}=\mathbf{0}$.

$\mathrm{V}_{30} \mathrm{ml}$. = Value of $\mathrm{V}$ at $\mathrm{t}=30$ minutes.

$1 / \overline{\mathrm{V}}_{30} \mathrm{ml} .^{-1}=$ Mean value of $1 / \mathrm{V}$ from $\mathrm{t}=0$ to 30 minutes.

$\mathrm{V}_{\mathrm{a}} \mathrm{N}_{\mathrm{o}} \mathrm{ml}$. = Apparent volume of iodide space, at time $t_{\mathrm{i}}$ that is "observed" in the extra-thyroidal neck tissues by the external counter.

W kg. = Weight of the patient.

$\phi=\overline{\mathrm{V}}_{30}$ times the average value of $1 / \mathrm{V}$ up to time $\mathrm{t}$.

\section{Basic equations}

Considering now the movement of a tracer dose, $\mathrm{d}$ mc. after injection at zero time $t=0$ as in Figure 3, the basic differential equation for the fraction $P$ remaining in the iodide space $\mathrm{V} \mathrm{ml}$. at time $t$ is clearly

$$
\frac{d P}{d t}=-\frac{a P}{V}
$$

where a $\mathrm{ml}$. per min. is the combined rate of clearance of plasma (13) obtained by adding together the thyroid and renal clearance rates, $\mathrm{g} \mathrm{ml}$. per $\mathrm{min}$. and $\mathrm{r} \mathrm{ml}$. per min., respectively.

Now avoiding the assumption of any particular functional form for the variation of $\mathrm{V}$ with time, but merely taking $\mathrm{V}$ as an unknown function of $t$, the solution of (1), with $P=1$ at $t=0$, is

$$
P=e^{-a} \int_{0}^{t d t}
$$

Now define a new function $\phi$ as the ratio of the average value of $1 / \mathrm{V}$ from time 0 to $t$ to the average value up to 
30 minutes $1 / \bar{V}_{20}$, so that

$$
\phi=\frac{30 \int_{0}^{t} \frac{d t}{V}}{t \int_{0}^{30} \frac{d t}{V}}=\frac{\bar{V}_{30}}{t} \int_{0}^{t} \frac{d t}{V}
$$

and write for the average total fractional rate of removal, $\mathrm{k} \mathrm{min} .^{-1}$, of radioiodide from the iodide space during the period 0 to 30 minutes

$$
k=a / \bar{V}_{30}
$$

Then equation (2) may be rewritten as

$$
P=e^{-k \phi t}
$$

Similarly the corresponding relations for the thyroidal and renal fractions may be shown to be

$$
\begin{aligned}
& G=\left(1-e^{-k \phi t}\right) k_{1} / k \\
& E=\left(1-e^{-k \phi t}\right) k_{2} / k
\end{aligned}
$$

where $k_{1}$ and $k_{2}$ min. $^{-1}$ are the average fractional rates of thyroidal uptake and renal removal over the same 30minute period. There is, of course, no necessity to choose the time of 30 minutes for the definition of $\phi$; we have done so because this is a convenient period for some uptake measurements, Berson, Yalow, Sorrentino, and Roswit (5) have already published results of tests made at this particular time after injection, and the choice of $t=0$ for the reference point leads to no real improvement because $V_{0}$ is subject to considerable experimental uncertainty.

The fractional rates $k_{1}$ and $k_{2}$ are related to the clearance rates by the ratios

$$
\begin{aligned}
& k_{1} / k=g / a \\
& k_{2} / k=r / a
\end{aligned}
$$

The $k$ value so obtained is identical to the disappearance rate in common use, except that a correction has been applied for the changing iodide space instead of assuming it to be constant.

In equilibrium, where the dietary input of stable iodide, $Q$ micrograms per day, equals the urinary output, the amount accumulated is $k Q / k_{2}$, or $g Q / r$ micrograms per day, so that it is immaterial whether $k$ values or clearance rates are used as parameters.

However, to utilize clearance rates, we must assume that the actual volumes themselves are constant, or some known function of body weight; whereas, when $\mathrm{k}$ values are found, it is assumed only that the relative changes of the volume of the iodide space are constant for all patients.

\section{Additional equations for uptake studies}

When uptake measurements are made by the usual external in vivo counting methods, to account for the observed radioiodine content $\mathrm{N}$ of the neck we must add together the thyroid fraction $\mathrm{G}$ and some contribution from the blood vessels and other extrathyroid tissues "visible" to the counter. This contribution is by no means negligible when low uptakes are involved, even at $t=24$ hours.

The simplest assumption to make, and the one that is implicit in Berson, Yalow, Sorrentino, and Roswit's (5) work, is that these neck tissues contain a constant share of the total iodide space $\mathrm{V}$ during the whole experiment. If this is so, they will contribute a constant portion of $P$, giving a combined effect of

$$
\mathrm{N}=\mathrm{N}_{0} \mathrm{P}+\mathrm{G}
$$

where $\mathrm{N}_{0}$ is the initial fraction of the dose observed in the neck, found from measurements extrapolated to $t=0$, at which time $G=0$ and $P=1$.

However, particularly at higher values of $t$ in hypothyroid or cardiac cases with low values of $k$, our experimental tests indicate that the observed neck tissues contain a proportional share of $\mathrm{V}$ that decreases as $\mathrm{V}$ increases by diffusion. Suppose, then, that the share of the neck tissues is proportional to a volume $V_{n}$, which does not increase with time as rapidly as $\mathrm{V}$, and that $\mathrm{V}_{\mathrm{n}}=\mathrm{V}=\mathrm{V}_{0}$ at $\mathbf{t}=\mathbf{0}$.

Then writing equation (10a) in the modified form

$$
\mathrm{N}=\mathrm{PN}_{\mathrm{O}} \mathrm{V}_{\mathrm{n}} / \mathrm{V}+\mathrm{G}
$$

and using (5) and ( $(5)$ it follows that

Since

$$
\mathrm{N}=\mathrm{N}_{\mathrm{O}} \mathrm{V}_{\mathrm{n}} \mathrm{e}^{-\mathbf{k} \phi t}+\left(1-\mathrm{e}^{-k \phi t}\right) \mathbf{k}_{1} / \mathbf{k}
$$

$$
\mathrm{k}=\mathrm{k}_{1}+\mathrm{k}_{2}
$$

equations (7) and (11) may be solved ${ }^{2}$ to give

and

$$
k_{1} / k=\frac{N-N_{0} V_{n} / V+E N_{0} V_{n} / V}{N-N_{0} V_{n} / V+E}
$$

$$
k \phi t=\ln \frac{k_{1} / k-N_{0} V_{n} / V}{k_{1} / k-N}=\ln \frac{1-N_{0} V_{n} / V}{1-N-E}
$$

Further, from the definition (3)

$$
\frac{1}{\mathrm{~V}}=\frac{\mathrm{d}(\phi \mathrm{t})}{\mathrm{dt}}\left(1 / \overline{\mathrm{V}}_{30}\right)=\frac{\mathrm{p}}{\mathrm{P}}=\mathrm{pe}^{\mathrm{k} \phi \mathrm{t}}
$$

where $\mathrm{p} \mathrm{ml.} .^{-1}$ is the fractional concentration of the dose remaining in the plasma.

In the simple case where $V_{n}=V$ the above relations should theoretically yield values of the unknowns $k_{1}, k_{2}$ and $V$ when a set of precise observations of $\mathrm{N}, \mathrm{E}$, and $\mathrm{P}$ is available.

In the more general case when $V_{n} \neq V$, the problem is not so easy. A possible line of approach, primarily to find $V_{n} / V$, is to conduct a series of observations after the thyroid uptake has been made substantially zero $\left(k_{1}=0\right)$ by the administration of large doses of stable ${ }^{17} I$ iodide.

${ }^{3}$ From (7) and (12) it follows that

and from (11)

$$
k_{1} / k=1-k_{2} / k=\frac{1-e^{-k \phi t}-E}{1-e^{-k \phi t}}
$$

so that

$$
k_{1} / k=\frac{N-N_{0}\left(V_{n} / V\right) e^{-k \phi t}}{1-e^{-k \phi t}}
$$

and

$$
N-N_{0}\left(V_{m} / V\right) e^{-k \phi t}=1-E-e^{-k \phi t}
$$

$$
e^{-k \phi t}=\frac{1-N-E}{1-N_{0} V_{n} / V}
$$

Equation (14) follows directly from (14a) and (13) is derived by substituting $(14 a)$ in $(13 a)$. 
For this series the equations become

$$
\begin{aligned}
N & =\frac{N_{0} V_{n}}{V} e^{-k_{2} \phi t} \\
\frac{V_{n}}{V} & =\frac{N}{N_{0}(1-E)} \\
k_{2} \phi t & =-\ln (1-E) \\
\frac{1}{V} & =p e^{k_{2} \phi t}=\frac{p}{1-E}
\end{aligned}
$$

\section{EXPERIMENTAL METHODS}

To test the applicability of the above formulae careful measurements are needed of the radioiodine in the neck, the plasma and the urine of selected patients over most of the period before radioactive hormone is released by the thyroid.

Various methods of making these measurements have been thoroughly described by others (13-16); our own arrangements closely resemble those of Berson, Yalow, Sorrentino, and Roswit (5) and of Loverdo (7), so they are described only briefly below.

Dose: From ${ }^{111}$, supplied by the Atomic Energy Commission at Oak Ridge, a carrier-free dose D mc. and a reference standard $\mathbf{R}$ mc. are prepared, each containing about $0.1 \mathrm{mc}$. in $5 \mathrm{ml}$. of solution in similar glass vials. The ratio $D / R$ is carefully measured by gamma counting, and later the residues left behind in the injection syringe and vial are also compared with $R$ so that the net dose $\mathrm{d}$ mc. injected can be found as a ratio $d / R$.

At the same time a further aliquot of the original solution is measured and diluted to serve as a standard for comparison with blood and urine samples.

Uptake measurement: For uptake observations a collimated scintillation counter is used at a long crystal-skin distance $(47 \mathrm{~cm}$.) to avoid large "inverse-square" errors. The lead collimator walls are $3.8 \mathrm{~cm}$. (1.5 inch) thick; its axial aperture has a minimum diameter of $1.27 \mathrm{~cm}$. $(0.5$ inch) and tapers outwards with a half-angle of $7.1^{\circ}$ so that a circle of $13.7 \mathrm{~cm}$. diameter is in full view of the crystal at $50 \mathrm{~cm}$. distance. A conical lead plug closes the aperture when background readings are taken. In all our preliminary experiments the axial length of the collimator was 3.8 $\mathrm{cm}$., after which it was extended by an added lead cone to a total length of $20 \mathrm{~cm}$. in order to lower the counts in the neck tissue by eliminating most of the penumbral region viewed by the crystal. These two arrangements will be referred to as the "short" and "long" collimators.

The counter is operated with an E. K. Cole precision ratemeter type N522, and its output is recorded continuously on a Brown type 153 chart-recorder. Recordings are also made for the purpose of calibration with the reference source $R$ at $47 \mathrm{~cm}$. distance, both before and after the in vivo observations. Corrections necessary for absorption and backscatter in the neck tissues were found as usual from a series of experiments with wax phantoms of different sizes.

The dose $d$ is given intravenously in a few seconds and the recording equipment or timing clock is started at zero time, which is taken when half the dose has entered the patient.
Plasma and urine assay: Most patients, particularly cardiac cases and those expected to have low $k$ values, are catheterized for urine collections up to 60 minutes after injection. The urine and plasma samples are all expressed in terms of the net dose $d$ after counting in a skirted Geiger counter (17) or in a well-type scintillation counter.

In fixing the time $t$ for the urine collections we have allowed a lag of 5 minutes between the time of excretion of urine by the kidneys and its collection in the bladder; thus urine collected 65 minutes after injection would be calculated as that up to $t=60$. The delay period of 5 minutes was used by Berson, Yalow, Sorrentino, and Roswit (5) and we also have confirmed its approximate accuracy by a few tests on some of our own patients.

\section{RESULTS}

Using the above methods we have made a series of tests to find the variation with time of the quantities $V_{n} / V, V$ and $\phi$ in a number of patients, as follows:

\section{Series $A$}

This series consisted of euthyroid and cardiac cases studied before, and in some cases again after, a course of Lugol's medication, with serial readings of the counting rate over the neck, and blood, and urine radioiodine assays at times $t$ of 0 to 30 minutes, 1, 2, 4, and 24 hours.

It was simplest to analyse the post-Lugol's results first, using equation (17) to find $V_{n} / V$, which is recorded as a ratio to the value $\left(V_{n} / V\right)_{2}$ at time $t=2$ minutes rather than $t=0$. This is necessary because the injected dose takes about one minute to mix with the circulating blood and the chart recorder trace shows an initial peak from the concentrated dose moving up the patient's arm and past the field of view of the counter. This peak, which is, of course, much larger with the short collimator than with the long one, must be allowed to die away quickly by using a short time-constant in the ratemeter circuit: one of our experimental cases in this series was spoilt for this reason, the time-constant control being switched too early to the 20 -second setting, thus making the recorded rate too high at $t=2$ minutes. Excluding this case, we have measured five others with the results shown in Figure 4. At $t=24$ hours we have found, for a total of eleven low-uptake cases, a mean value of $\frac{V_{n} / V}{\left(V_{n} / V\right)_{2}}=0.52 \pm 0.18(S . D$.$) . Of these cases,$ four showed positive edema and the other seven were nonedematous. The range of values was 


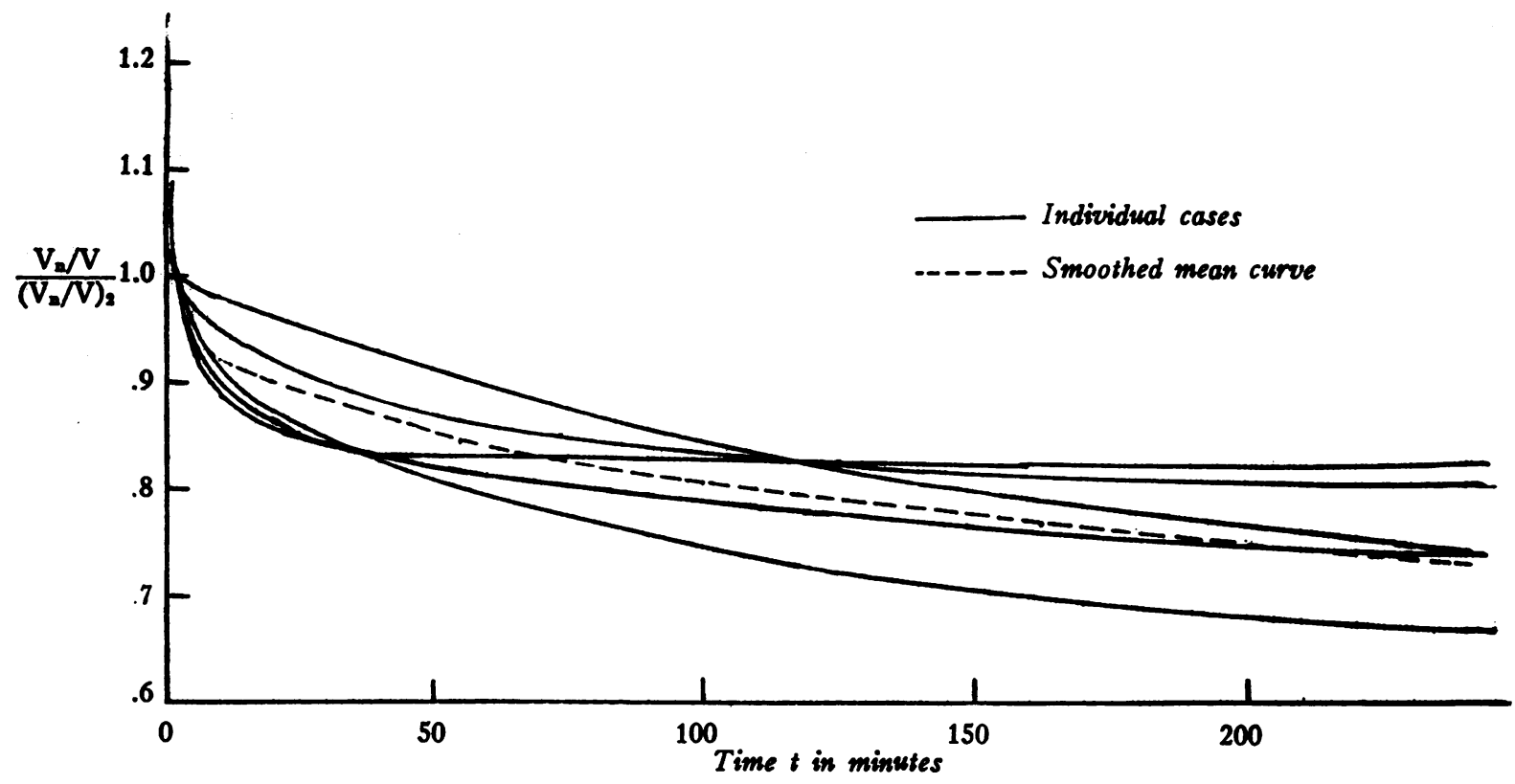

Fig. 4. Effective Neck Volumg Ratio Found in Five Expernorgtal Patients Whose Thyroid Glands Were Saturated with Lugol's SOlution

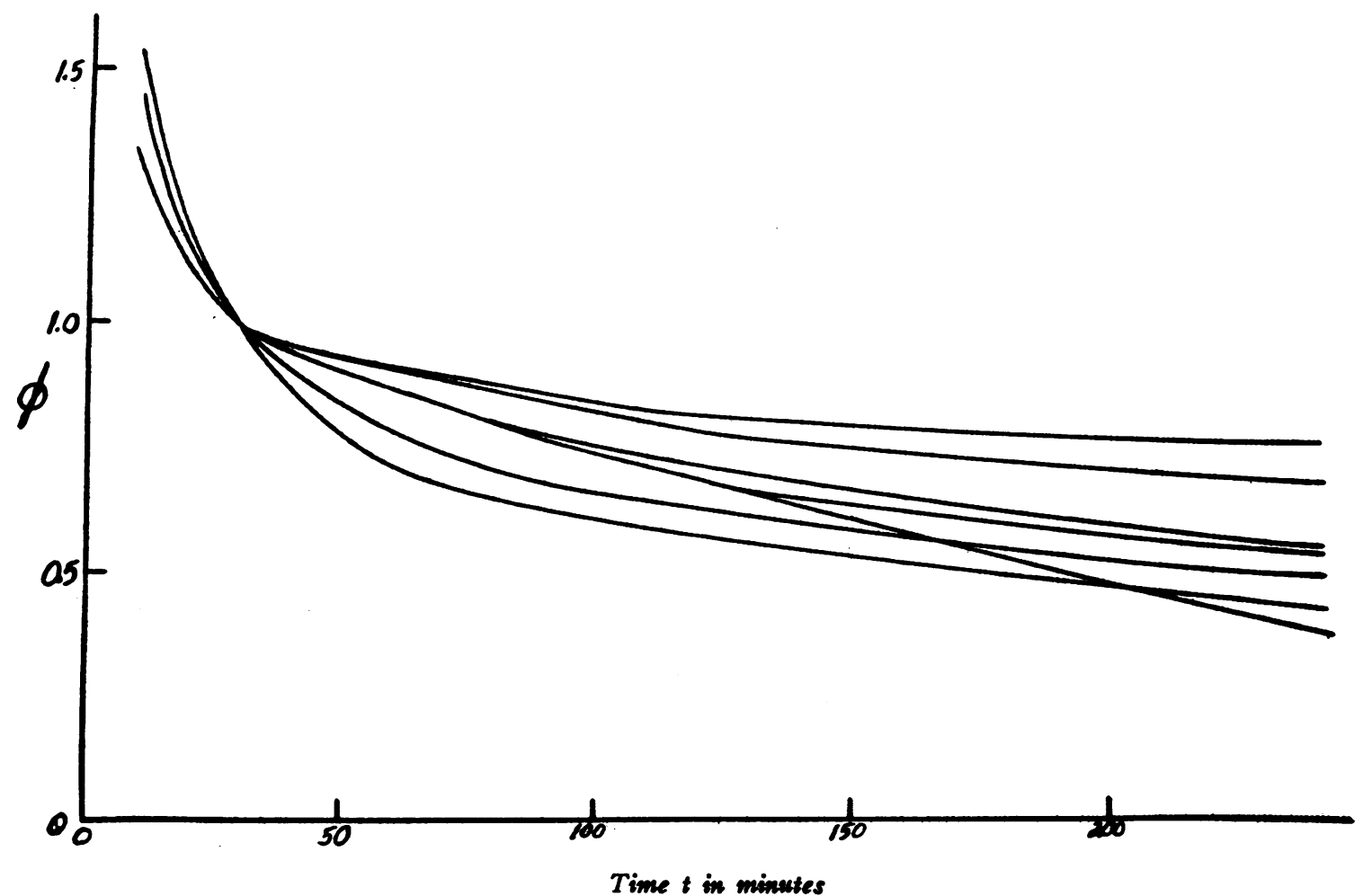

Fig. 5. Expernorntal Curves for $\phi$

Fig. 5A. Results for Low a Values, Series A 


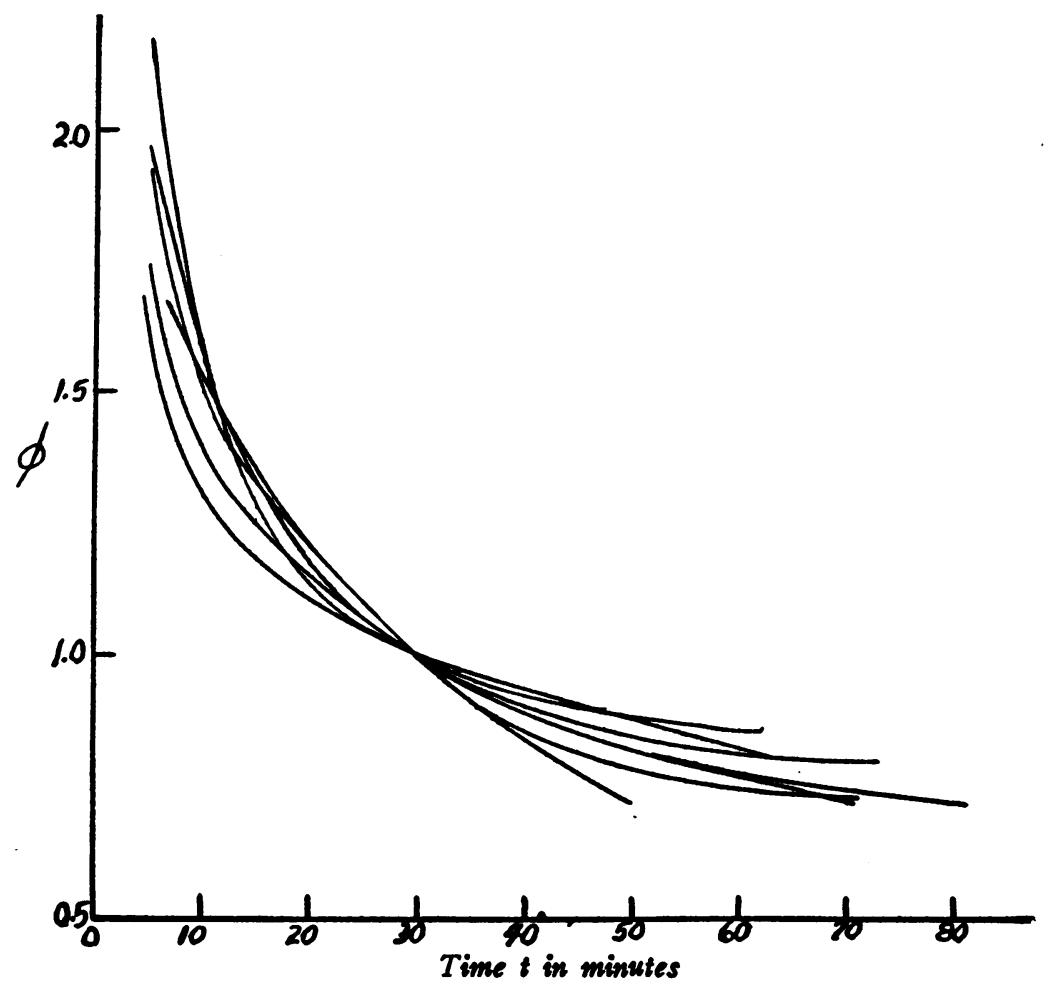

Fig. 5b. Results for Higa k Values, Series B

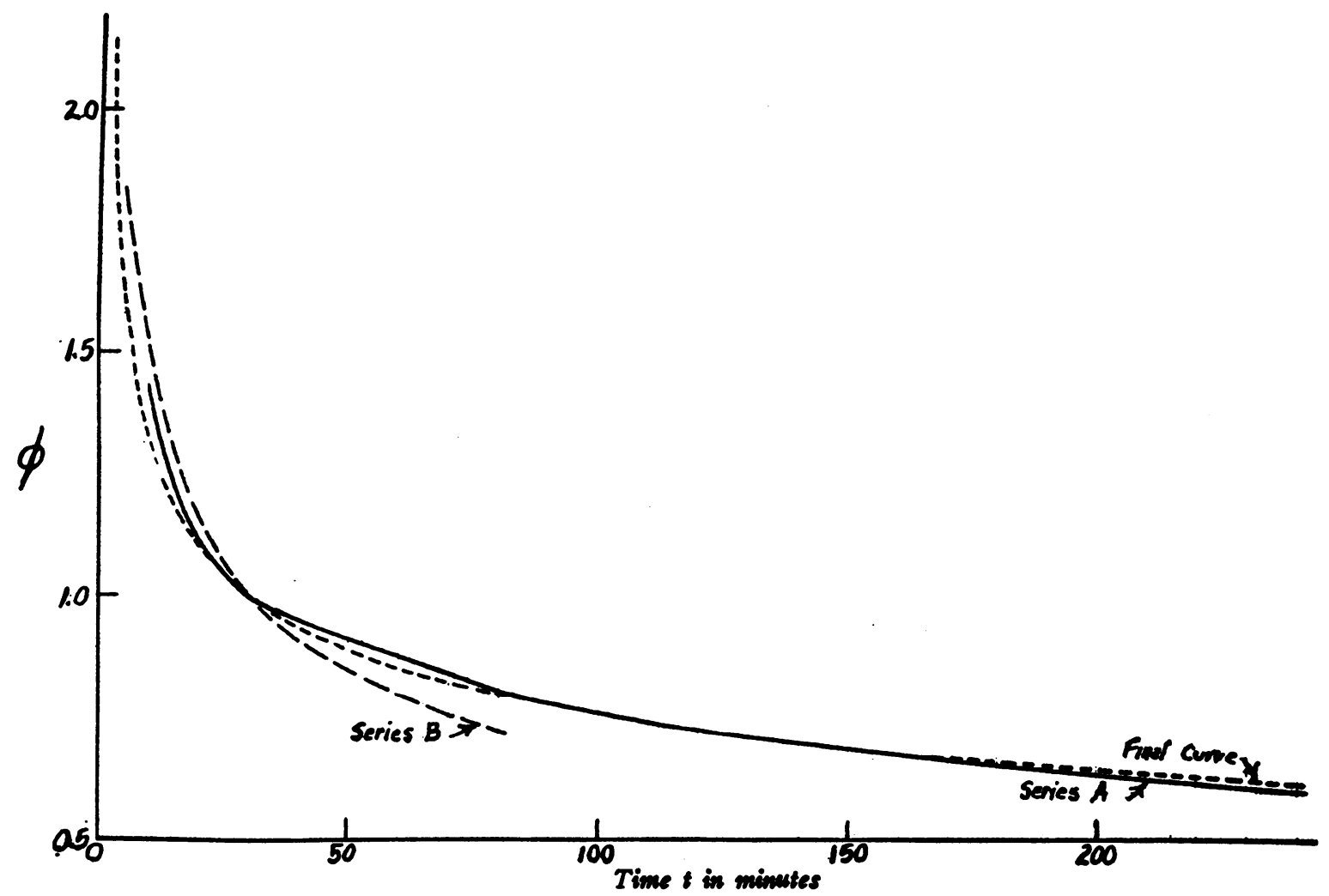

Fig. 5c. Mean Curves and Final $\phi$ Curve 
wide (from -0.16 to +1.86 ) mainly, we consider, because measurements of this quantity at $t=24$ hours are obviously experimentally difficult with the low values of both $N$ and $(1-E)$ encountered in practice. However, for the same reason the actual value is not as important as it is with earlier observations.

In Figures 4 and 7 the mean curve is given for $\frac{V_{n} / V}{\left(V_{n} / V\right)_{2}}$ and smoothed values of this ratio are included in Table III.

To deal with the pre-Lugol's results, using equations (13) and (14), it was necessary first to deduce the value of $\mathrm{N}_{0} \mathrm{~V}_{\mathrm{n}} / \mathrm{V}$. There are several ways of doing this; in the present instance sufficient accuracy was given by approximating equation (11) to the form

$$
\mathrm{N}_{0} \mathrm{~V}_{\mathrm{n}} / \mathrm{V}=\frac{\mathrm{V}_{\mathrm{n}} / \mathrm{V}}{\left(\mathrm{V}_{\mathrm{n}} / \mathrm{V}\right)_{2}}\left(\mathrm{~N}_{2}-\mathrm{k}_{1} \phi \mathrm{t}\right)
$$

and using the observed value of $\mathrm{N}_{2}$ with an approximate value of $\mathrm{k}_{1} \phi \mathrm{t}$.
TABLE I

\begin{tabular}{llllllll}
\hline Before Lugol's & 0.85 & 0.28 & 1.2 & 3.5 & 1.8 & $\times 10^{-8}$ & $\mathrm{~min}$. \\
After Lugol's & 2.1 & 0.60 & 1.0 & 4.0 & 1.2 & $\times 10^{-3}$ & $\mathrm{~min}^{-1}$
\end{tabular}

By this means, for the same patient, preLugol's values of $\phi$ were found, which agreed reasonably well with post-Lugol's values already deduced from equation (18). On the other hand the renal rates $k_{2}$ were not found to be the same, corresponding pairs of values being shown in Table I.

The mean experimental curves for $\phi$ for seven patients in this series are shown in Figure 5 (a), while the mean curve for the volume of the iodide space $\mathrm{V}$, calculated from the plasma assays in sixteen serial observations (eleven patients), is shown in Figure 6.

\section{Series $B$}

A second series of eight "high-k" hyperthyroid cases has been examined to find the early part

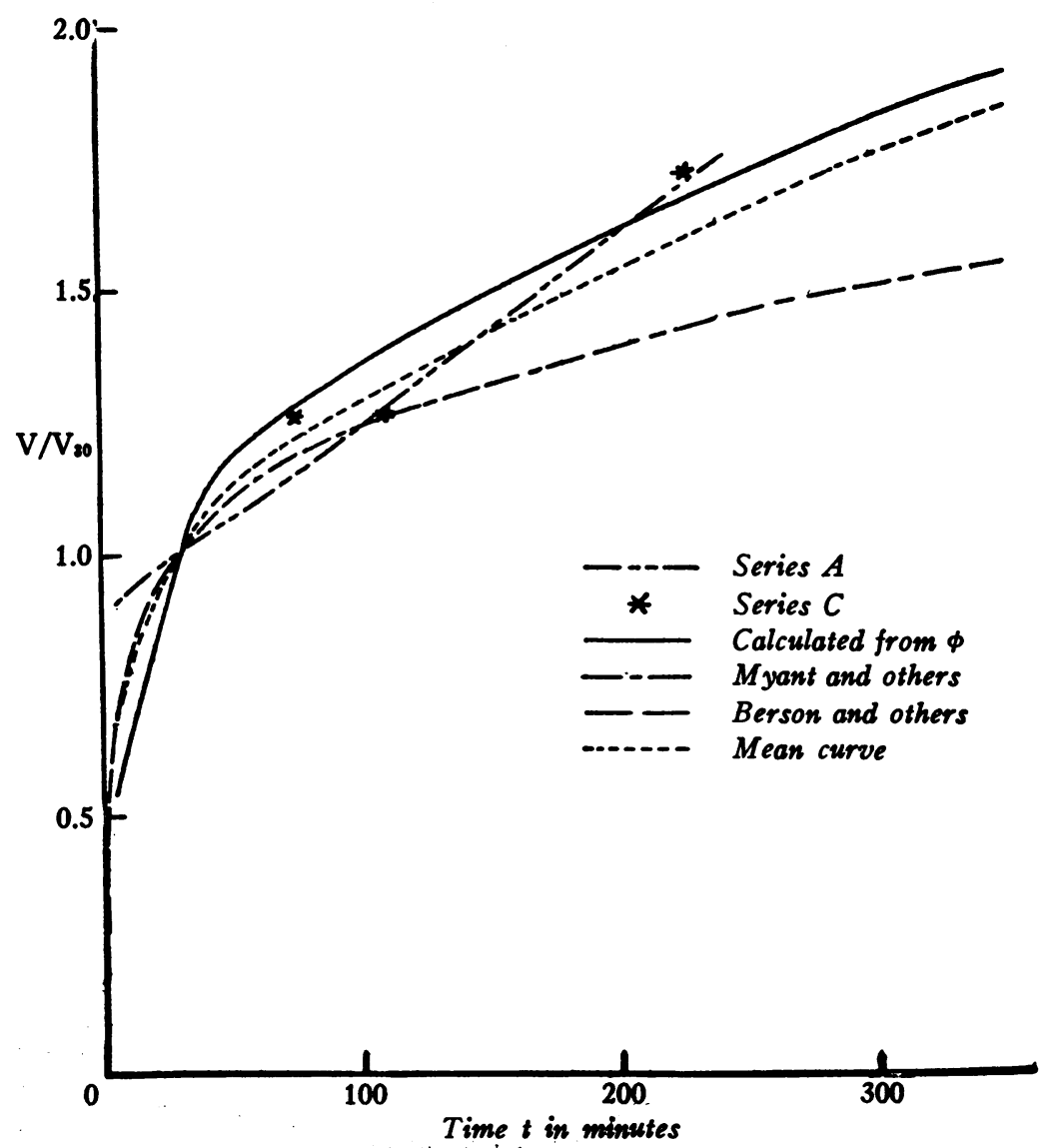

Fig. 6. Data on Volunge Ratio $\mathrm{V} / \mathrm{V}_{\boldsymbol{w}}$ 


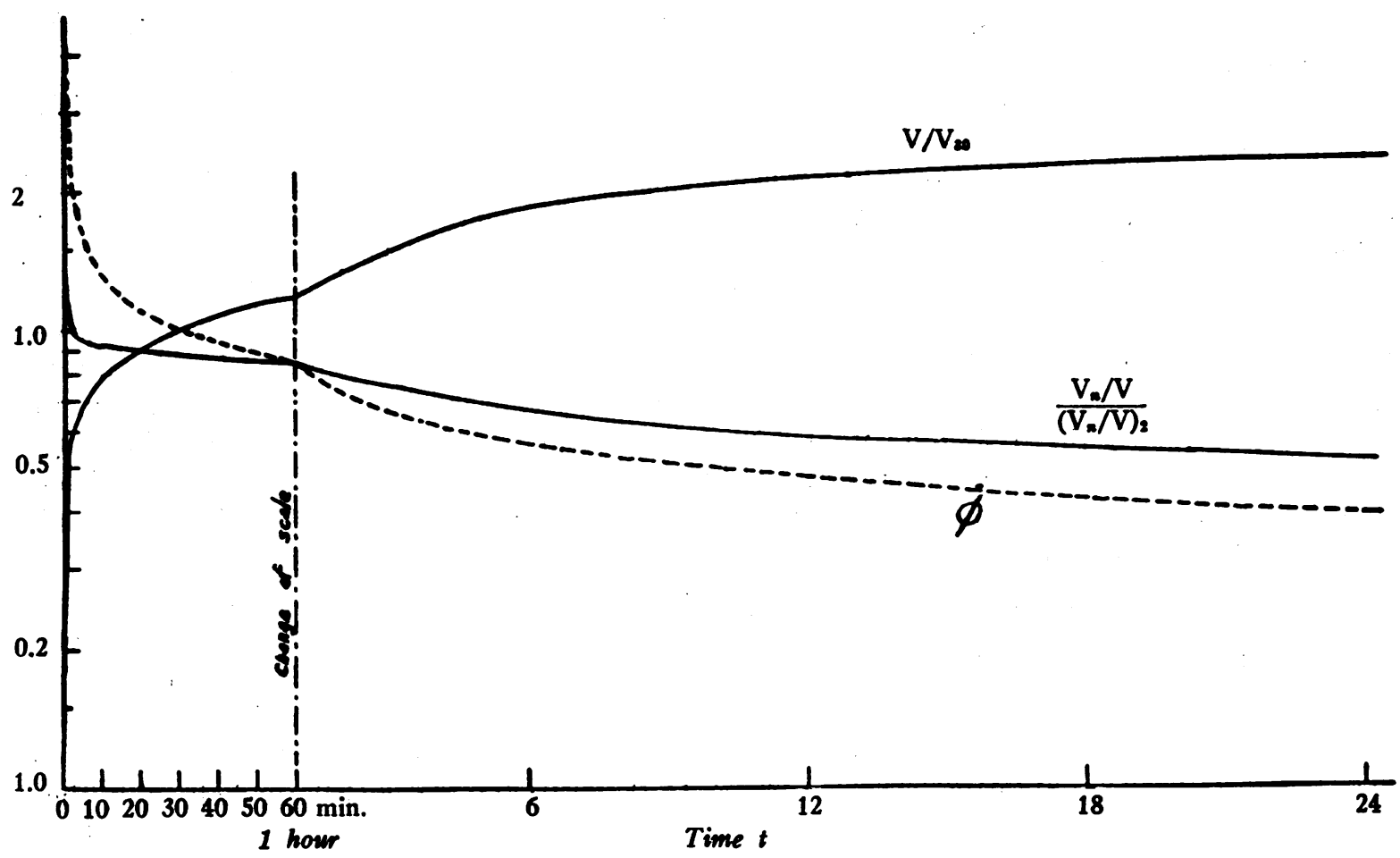

Fig. 7. Final Syoothed Curves for Volume Ratios and $\phi$

of the $\phi$ curve. Observations of the neck uptake were recorded continuously up to about $\mathrm{t}=60$ minutes, and urine and blood samples were also measured.

The $\phi$ values, calculated as described for series A, are shown in Figure 5 (b), and in Figure 5 (c) the mean value is compared with the mean curve from series $A$ and with the overall mean curve finally adopted as described later.

\section{Series $C$}

The remaining group we have examined comprises a miscellaneous group of thirty-six normal and "low-k" cardiac or athyroid cases, for which we have made observations of the iodide space volume $\mathrm{V}$ at one or two times after injection. The mean results, expressed as the ratio of $\mathrm{V}$ to $\mathrm{V}_{\mathbf{3 0}}$, its instantaneous value at $\mathbf{3 0}$ minutes, are given in Table II.

TABLB II *

\begin{tabular}{lrrrrr}
\hline \hline Mean t minutes & 30 & 76 & 110 & 228 & 1440 \\
Mean V/V $/ 20$ & 1.00 & 1.26 & 1.26 & 1.71 & 2.01 \\
Number of cases & - & 25 & 2 & 3 & 14
\end{tabular}

\footnotetext{
* These points are also plotted separately in Figure 6.
}

\section{DISCUSSION}

The quantity $\phi$ is of major interest in this investigation because errors in $\phi$ directly affect the measured rates $k_{1}$ and $k_{2} ; \phi$ can be derived from the volume ratios $V / \mathrm{V}_{30}$ as well as from the direct measurements, but the absolute value of $\mathrm{V}$ is not needed unless it is desired to calculate clearance rates ( $\mathrm{g}$ and $\mathrm{r}$ ).

To correlate the available information we have proceeded as follows:

(a) The mean results found directly for $\phi$ in our test series $A$ and $B$ were used to give a smooth curve for $\phi$ against $t$, from which $V / V_{30}$ was deduced with the help of equation (15).

(b) Direct measurements of $\mathrm{V}$ by plasma assay in series $\mathrm{A}$ provided independently another time curve for $\mathrm{V} / \mathrm{V}_{20}$, and series $\mathrm{C}$ gave further isolated points.

(c) A search of the published literature yielded information from Myant, Corbett, Honour, and Pochin (18) on twelve cases over the range of $t$ from 30 to 360 minutes, and from Berson, Yalow, Sorrentino, and Roswit (5) on seven cases over the range 0 to 30 minutes. 
(d) From the above data mean points were calculated for various times $t$, giving weight to the several sources of information in proportion to the number of cases. The smoothed curve drawn through these points is shown in Figures 6 and 7, and final smoothed values of $V / V_{30}$ are included in Table III.

(e) Finally these last smoothed figures for $\mathrm{V} / \mathrm{V}_{\mathbf{3 0}}$ have been converted back to $\phi$ by equation (3) with the results shown in Figures 5 and 7 and Table III.

Table III gives all the basic data needed to find rates $k, k_{1}$, and $k_{2}$. Clearance rates follow from these by multiplying by $\nabla_{30}$ which is given, in our correlated results, by

$$
\nabla_{30}=V_{30} / 1.32
$$

For $\mathrm{V}_{30}$ in turn, expressed in terms of the body weight W $\mathrm{Kg}$., we have

$$
\begin{aligned}
& \mathrm{W} / \mathrm{V}_{30}=4.10 \mathrm{Kg} \text {./litre-Reference number (18) } \\
& -12 \text { cases } \\
& 3.85 \text {-Reference number (5) } \\
& 2.92 \quad-\text { This paper-44 cases }
\end{aligned}
$$

\begin{tabular}{|c|c|c|c|c|}
\hline minutes & $V / V_{20}$ & $\phi$ & $\phi \mathrm{t}$ & $\frac{V_{n} / V}{\left(V_{n} / V_{z}\right.}$ \\
\hline $\begin{array}{r}0 \\
2 \\
5 \\
10 \\
15 \\
20 \\
30 \\
40 \\
50 \\
60 \\
70 \\
80 \\
90 \\
100 \\
120 \\
140 \\
160 \\
180 \\
200 \\
240 \\
300 \\
360 \\
480 \\
600 \\
720 \\
1080 \\
1440\end{array}$ & $\begin{array}{l}(0.18) \\
0.58 \\
0.68 \\
0.78 \\
0.85 \\
0.90 \\
1.00 \\
1.08 \\
1.13 \\
1.17 \\
1.20 \\
1.23 \\
1.26 \\
1.29 \\
1.34 \\
1.39 \\
1.44 \\
1.49 \\
1.53 \\
1.63 \\
1.76 \\
1.86 \\
2.00 \\
2.11 \\
2.20 \\
2.36 \\
2.45\end{array}$ & $\begin{array}{l}(4.2) \\
2.15 \\
1.58 \\
1.31 \\
1.18 \\
1.10 \\
1.00 \\
0.932 \\
0.885 \\
0.846 \\
0.816 \\
0.792 \\
0.772 \\
0.754 \\
0.725 \\
0.700 \\
0.679 \\
0.661 \\
0.645 \\
0.617 \\
0.582 \\
0.555 \\
0.515 \\
0.486 \\
0.463 \\
0.419 \\
0.393\end{array}$ & $\begin{array}{r}0.0 \\
4.3 \\
7.9 \\
13.1 \\
17.7 \\
22.0 \\
30.0 \\
37.3 \\
44.2 \\
50.8 \\
57.1 \\
63.4 \\
69.5 \\
75.4 \\
87.0 \\
98.0 \\
109 \\
119 \\
129 \\
148 \\
175 \\
200 \\
247 \\
292 \\
333 \\
453 \\
566\end{array}$ & $\begin{array}{l}(1.34) \\
1.00 \\
0.95 \\
0.92 \\
0.91 \\
0.90 \\
0.88 \\
0.87 \\
0.86 \\
0.84 \\
0.83 \\
0.82 \\
0.81 \\
0.80 \\
0.79 \\
0.78 \\
0.77 \\
0.76 \\
0.75 \\
0.72 \\
0.69 \\
0.66 \\
0.62 \\
0.59 \\
0.57 \\
0.54 \\
0.52\end{array}$ \\
\hline
\end{tabular}

TABLE III

Mean smoothed values of various factors for uptake calculations *

* For interpretation of symbols, see Text. with a weighted mean value of 3.25 giving $V_{30}$ as 31 per cent of the body weight.

Thirteen of the cases studied showed positive edema and had an average $\mathrm{W} / \mathrm{V}_{30}$ of 2.69 which is somewhat lower than the overall average, but we did not observe any systematic effect of edema on the individual values of $\mathrm{V}$ at different times $\mathrm{t}$.

The ratio $\mathrm{W} / \mathrm{V}_{30}$ is not particularly constant from patient to patient and it seems that its use to find clearance rates instead of fractional rates $\mathbf{k}$ will not gain in diagnostic accuracy. On the other hand, we feel that the data obtained on $\phi$ and the volume ratios are sufficiently consistent amongst themselves and with the other published results to enable the equations presented to be used for the calculation of the $k$ rates. It must be emphasized that the calculation of $\mathbf{k}$ does not require a knowledge of the absolute value of the volume $\mathrm{V}$ of the iodide space, but only of the relative changes of $\mathrm{V}$ with the time $\mathrm{t}$. In the following paper (19) we shall apply these data to the development of convenient tables to simplify the routine measurement and calculation of uptake rates, and in a later publication an attempt will be made to correlate diagnostic limits deduced from the published work of others.

\section{SUMMARY}

The early metabolism of iodide in the human body is discussed on a mathematical basis with the object of improving the accuracy of diagnostic tests of thyroid conditions with radioiodine. Allowance is made for changes in the iodide space and the effective volume of neck tissues observed by external gamma ray counting at various times after the administration of the test dose. After testing the resulting equations by experiments on a series of patients, the mean test results are combined with data deduced from the publications of other workers to give tabulated information suitable for practical use.

\section{ACKNOWLEDGMENTS}

We appreciate very much the assistance of Mrs. M. Bates and Mr. C. C. Young in carrying out the tests described, and of Mr. C. Jackson and Mr. L. F. Muench in the construction and maintenance of the necessary apparatus. 


\section{REFERENCES}

1. Riggs, D. S., Quantitative aspects of iodine metabolism in man. Pharmacological Rev., 1952, 4, 284.

2. Haigh, C. P., and Reiss, M., II. Some applications of $\mathrm{I}^{131}$ and $\mathrm{Na}^{24}$ to clinical diagnosis. Brit. J. Radiol., 1950, 23, 534.

3. Haigh, C. P., and Reiss, M., Recent developments in the measurement of thyroid function using radioiodine. J. Endocrinol., 1951-2, 8, xxi.

4. Reiss, M., Haigh, C. P., Hemphill, R. E., Maggs, R., Reiss, J. M., and Smith, S., Studies of the human thyroid function, measured by radio-iodine, and its relation to the basal metabolic rate. J. Endocrinol., 1951-2, 8, 1.

5. Berson, S. A., Yalow, R. S., Sorrentino, J., and Roswit, B., The determination of thyroidal and renal plasma $I^{131}$ clearance rates as a routine diagnostic test of thyroid disfunction. J. Clin. Invest., 1952, 31, 141.

6. Clarke, K. H., and Aujard, R. L., Thyroid symposium III: The use of radioactive iodine $I^{131}$ in the diagnosis of hyperthyroidism: physical aspects. M. J. Australia, 1954, 1, 891.

7. Loverdo, A., Iodine metabolism tracing techniques. "Radio-isotope techniques." London, Her Majesty's Stationery Office, 1953, vol. I, p. 243.

8. Brownell, G. L., Analysis of techniques for the determination of thyroid function with radioiodine. $\mathrm{J}$. Clin. Endocrinol., 1951, 11, 1095.

9. Oddie, T. H., Analysis of radio-iodine uptake and excretion curves. Brit. J. Radiol., 1949, 22, 261.

10. Oddie, T. H., Metabolic equations for radio-iodine tests. Commonwealth of Australia, X-Ray and
Radium Laboratory, Technical Communication No. 41, 1950.

11. Rotblat, J., and Marcus, R., Clinical uses of radioiodine. "Radioisotope techniques." London, Her Majesty's Stationery Office, 1953, vol. I, p. 33.

12. Wollman, S. H., A thyroid model describing kinetics of exchange, concentrating, and organic binding of iodide. Endocrinology, 1954, 54, 35.

13. Myant, N. B., Pochin, E. E., and Goldie, E. A. G., The plasma iodide clearance rate of the human thyroid. Clin. Sc., 1949, 8, 109.

14. Freedberg, A. S., Chamovitz, D. L., and Kurland, G. S., Thyroid function in normal and pathological states as revealed by radioactive iodine studies. I. Thyroid I $^{131}$ uptake and turnover in euthyroid, hyperthyroid, and hypothyroid subjects. Metabolism, 1952, 1, 26.

15. Myant, N. B., Honour, A. J., and Pochin, E. E., The estimation of radioiodine in the thyroid gland of living subjects. Clin. Sc., 1949, 8, 135.

16. Oddie, T. H., and Scott, R. K., External measurement of radio-iodine in the thyroid gland. Brit. J. Radiol., 1949, 22, 698.

17. Veall, N., A Geiger-Muller counter for measuring the beta-ray activity of liquids, and its application to medical tracer experiments. Brit. J. Radiol., 1948, $21,347$.

18. Myant, N. B., Corbett, B. D., Honour, A. J., and Pochin, E. E., Distribution of radioiodide in man. Clin. Sc., 1950, 9, 405.

19. Oddie, T. H., Meschan, I., and Wortham, J., Thyroid function assay with radioiodine. II. Routine calculation of thyroidal and renal rate factors. J. Clin. Invest., 1955, 34, 106. 